\title{
ПРАВОТВОРЧЕСКИЙ ПРОЦЕСС: НЕКОТОРЫЕ АСПЕКТЫ ПОНЯТИЙНО-КАТЕГОРИАЛЬНГО АППАРАТА
}

\author{
(c) 2018 Даова Фатима Хазреталиевна \\ Институт права, экономики и финансов \\ Кабардино-Балкарский государственный университет имени Х.М. Бербекова \\ 360004, г. Нальчик, ул. Чернышевского 173 \\ (C) 2018 Шаваева Диана Вячеславовна \\ Институт права, экономики и финансов \\ Кабардино-Балкарский государственный университет имени Х.М. Бербекова \\ 360004, г. Нальчик, ул. Чернышевского 173 \\ (C) 2018 Литягина Алла Сергеевна \\ старший преподаватель \\ Институт права, экономики и финансов \\ Кабардино-Балкарский государственный университет имени Х.М. Бербекова \\ 360004, г. Нальчик, ул. Чернышевского 173 \\ (c) 2018 Кокова Лиана Руслановна \\ доцент \\ Институт права, экономики и финансов \\ Кабардино-Балкарский государственный университет имени Х.М. Бербекова \\ 360004, г. Нальчик, ул. Чернышевского 173 \\ (c) 2018 Куашев Артур Каншобиевич \\ Судья \\ Чегемский районный суд \\ Кабардино-Балкарская Республика
}

В статье рассматриваются теоретические аспекты правотворческого процесса как конституционно-правового института Российского демократического федеративного правового государства, а также проводится содержательная дифференциация таких составных правовых категорий как «законотворческий процесс» и «законодательный процесс». Раскрываются формы взаимодействия государства и гражданского общества в сфере законодательной политики на стадии формирования юридических норм.

Ключевые слова: правотворческий процесс, законотворческий процесс, законодательный процесс, законопроектный процесс, законопроект, идея законопроекта, концепция законопроекта, нормативно-правовой акт, закон, гражданская законодательная инициатива, народная правотворческая иницииатива.

Правотворческий процесс как конституционно-правовой институт является выражением демократических черт современной российской государственности, подчинен принципам правового социального государства. Законность, гуманизм, научность, профессионализм, планирование законодательной деятельности являются основополагающими краеугольными идеями, которые определяют эвристический характер правотворческой процедуры и содержание правотворческой деятельности.

Соответственно целью данной работы яв- ляется изучение концепции правотворческого процесса в Российской Федерации, его структурных компонентов организационно-процессуальной деятельности, а так же соотношение содержания конституционно-правовых институтов народной и гражданской инициативы.

Исходя из современного этического понимания права, правотворческий процесс должен пониматься как более широкая юридикофилософская категория, средство резюмирования предшествующего законодательного опыта и как синтезирующая деятельность, которая акку- 
мулирует в себе такие понятия как «законотворчество» И «законодательный процесс» (рисунок $1)$.

В настоящее время законодательный процесс является формально юридическим выражением правотворческой функции государства [1]. Он выступает в качестве технического инструмента создания закона. Однако, несмотря на существенное значение данного процесса, отсутствует его четкое легальное определение. В связи с этим, авторами предлагается следующие определение: законодательный процесс - это совокупность регламентированных процессуальных действий высшего законодательного органа государственной власти и законодательного органа государственной власти субъекта Российской Федерации по принятию законов, состоящая из ряда последовательных, логически завершенных этапов от внесения законопроекта до введения его в действие в качестве закона, а также являющаяся составной частью процесса правотворчества.

Из представленной табл. 1 видно, что начальным и ключевым этапом законодательного процесса является внесение законопроекта. В своей работе В.И. Чехарина указывает, что законодательная инициатива непосредственно «связана с самой процедурой принятия закона» и данный институт необходим для определения границ законодательной процедуры. Однако необходимо также демаркировать понятия «гражданская инициатива» и «народная инициатива», поскольку указанные категории не являются «монохромными» в своем содержании.

Помимо вышерассмотренных юридических категорий, довольно часто как в доктринальных исследованиях, так и в нормативной базе встречаются понятия «идея законопроекта», «концепция законопроекта»,- как они взаимосвязаны, являются ли данные понятия «монохромными» в своем содержании, и есть ли практическая ценность раскрытия их семантических нагрузок и реализации в правотворческой деятельности?

Идея законопроекта - относительно самостоятельный прием законотворческой техники, применяемый для обозначения организационно суверенной начальной стадии законотворческой деятельности, представляющей собой систему теоретически обоснованных, практически апробированных суждений о необходимости принятия новых либо изменения или отмены действующих правовых норм. Идея законопроекта, тем самым, выступает как «катализирующее директивное начало» законотворческого процесса. Задачей идеи законопроекта является общая превенция: предупреждение возникновения коллизий, отрицательно влияющих на результаты законопроектной деятельности и выработка согласованных позиций по наиболее полемичным моментам проекта закона.

В юридической литературе «идея законопроекта» порой неосновательно отождествляется с его концепцией. В действительности концепция законопроекта имеет принципиально иные

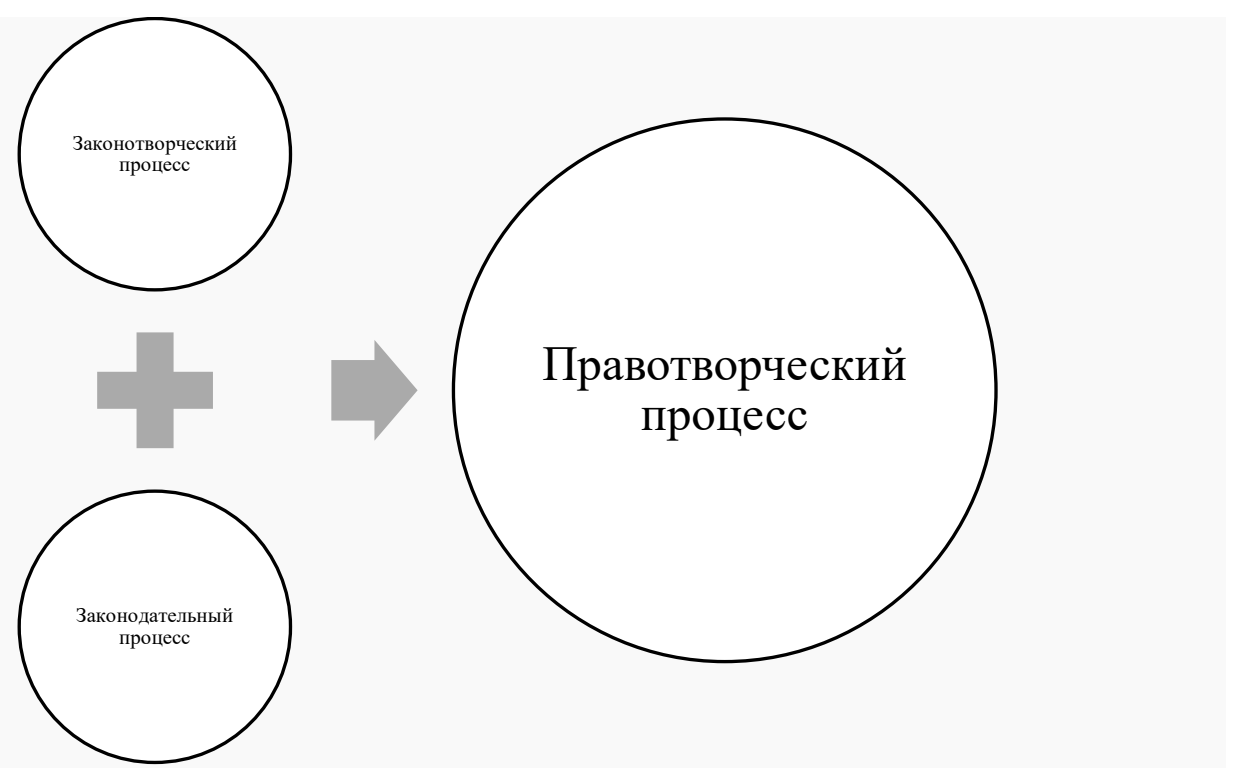

Puc. 1. Составные части правотворческого процесса 
Таблица 1. Соотношение понятийных категорий «правотворческий процесс», «законотворческий процесс» и «законодательный процесс»

\begin{tabular}{|c|c|c|c|}
\hline $\begin{array}{c}\text { Отличительные } \\
\text { признаки }\end{array}$ & $\begin{array}{l}\text { Правотворческий (нор- } \\
\text { мотворческий) процесс }\end{array}$ & $\begin{array}{c}\text { Законотворческий про- } \\
\text { цесс }\end{array}$ & $\begin{array}{c}\text { Законодательный } \\
\text { процесс }\end{array}$ \\
\hline $\begin{array}{l}\text { 1. Субъектный со- } \\
\text { став }\end{array}$ & $\begin{array}{l}\text { 1. государственные органы } \\
\text { (парламент, правитель- } \\
\text { ство); } \\
\text { 2. Конституционный Суд и } \\
\text { Верховный Суд; } \\
\text { 3. органы местного самоу- } \\
\text { правления; } \\
\text { 4. отдельные должностные } \\
\text { лица (президент, ми- } \\
\text { нистр); } \\
\text { 5. негосударственные } \\
\text { структуры (предприятия, } \\
\text { учреждения, организа- } \\
\text { ции); } \\
\text { 6. общественные организа- } \\
\text { ции (профсоюзы); } \\
\text { 7. граждане. }\end{array}$ & $\begin{array}{l}\text { Неограниченный круг } \\
\text { субъектов. Непосредствен- } \\
\text { ный автор идеи (концепта) } \\
\text { будущего закона (иници- } \\
\text { ативная группа граждан, } \\
\text { научное учреждение, груп- } \\
\text { па экспертов и специали- } \\
\text { стов, специализированный } \\
\text { центр законотворчества, } \\
\text { отраслевые министерства } \\
\text { и другие исполнительные } \\
\text { органы государственной } \\
\text { власти). }\end{array}$ & $\begin{array}{l}\text { 1. высший законодатель- } \\
\text { ный орган государствен- } \\
\text { ной власти (парламент); } \\
\text { 2. законодательный орган } \\
\text { государственной власти } \\
\text { субъекта РФ. }\end{array}$ \\
\hline 2. Начальная стадия & $\begin{array}{l}\text { Анализ состояния вопроса } \\
\text { (регулируемых обществен- } \\
\text { ных отношений). }\end{array}$ & $\begin{array}{l}\text { Анализ состояния вопроса } \\
\text { (регулируемых обществен- } \\
\text { ных отношений). }\end{array}$ & Внесение законопроекта. \\
\hline $\begin{array}{l}\text { 3. Заключительная } \\
\text { стадия }\end{array}$ & $\begin{array}{l}\text { Правовой мониторинг (мо- } \\
\text { ниторинг действия закона, } \\
\text { в том числе его реализация } \\
\text { и оценка эффективности). }\end{array}$ & Правовой мониторинг. & $\begin{array}{l}\text { Введение нормативного } \\
\text { правового акта в действие. }\end{array}$ \\
\hline $\begin{array}{l}\text { 4. Вид деятельности } \\
\text { (стадии) }\end{array}$ & $\begin{array}{l}\text { Интеллектуально-мысли- } \\
\text { тельная и формально-юри- } \\
\text { дическая деятельность. }\end{array}$ & $\begin{array}{l}\text { Интеллектуально-мысли- } \\
\text { тельная деятельность. } \\
\text { 1. анализ существующего } \\
\text { состояния регулирования } \\
\text { общественных отношений } \\
\text { и выявление проблем и } \\
\text { коллизий, подлежащих } \\
\text { разрешению законода- } \\
\text { тельными средствами; } \\
\text { 2. разработка концепции } \\
\text { законопроекта (законо- } \\
\text { предложение); } \\
\text { 3. непосредственное } \\
\text { изготовление аутентично- } \\
\text { го текста законопроекта } \\
\text { (законопректный процесс, } \\
\text { правовое моделирование); } \\
\text { 4. правовое прогнозирова- } \\
\text { ние законопроекта; } \\
\text { 5. правовой мониторинг. }\end{array}$ & $\begin{array}{l}\text { Формально-юридическая } \\
\text { деятельность. } \\
\text { 1. внесение законопроекта } \\
\text { (законодательная иници- } \\
\text { атива); } \\
\text { 2. рассмотрение законо- } \\
\text { проекта; } \\
\text { 3. обсуждение и принятие } \\
\text { законопроекта; } \\
\text { 4. рассмотрение Советом } \\
\text { Федерации закона, при- } \\
\text { нятого Государственной } \\
\text { Думой; } \\
\text { 5. создание согласитель- } \\
\text { ных комиссий (в случае } \\
\text { необходимости преодоле- } \\
\text { ния разногласий); } \\
\text { 6. промульгация (подпи- } \\
\text { сание и обнародование } \\
\text { (санкционирование) } \\
\text { закона; } \\
\text { 7. вступление в силу зако- } \\
\text { на. }\end{array}$ \\
\hline $\begin{array}{l}\text { 5. Нормативно-целе- } \\
\text { вое прогнозирование }\end{array}$ & $\begin{array}{l}\text { Конкретное представле- } \\
\text { ние о конечной редакции } \\
\text { закона. }\end{array}$ & $\begin{array}{l}\text { Абстрактное представле- } \\
\text { ние конечной редакции } \\
\text { закона. }\end{array}$ & $\begin{array}{l}\text { Конкретное представле- } \\
\text { ние о конечной редакции } \\
\text { закона. }\end{array}$ \\
\hline
\end{tabular}


Таблица 2. Соотношение понятий «народная правотворческая инициатива» и «гражданская законодательная инициатива»

\begin{tabular}{|c|c|c|}
\hline $\begin{array}{c}\text { Отличительные } \\
\text { признаки }\end{array}$ & $\begin{array}{c}\text { Народная правотворческая } \\
\text { инициатива }\end{array}$ & $\begin{array}{c}\text { Гражданская законодательная } \\
\text { инициатива }\end{array}$ \\
\hline 1. Уровень & Региональный, муниципальный & Федеральный \\
\hline 2. Форма & $\begin{array}{l}\text { 1. предложения } \\
\text { 2. заявления } \\
\text { 3. жалобы }\end{array}$ & $\begin{array}{l}\text { 1. индивидуальная петиция (жалоба, про- } \\
\text { шение) } \\
\text { 2. коллективная петиция (жалоба, ходатай- } \\
\text { ство) }\end{array}$ \\
\hline $\begin{array}{l}\text { 3. Субъектный } \\
\text { состав }\end{array}$ & $\begin{array}{l}\text { 1. инициативная группа граждан; } \\
\text { 2. представительные органы других му- } \\
\text { ниципальных образований, находящихся } \\
\text { в границах территории муниципального } \\
\text { образования; } \\
\text { 3. органы территориального обществен- } \\
\text { ного самоуправления; 4. общественные } \\
\text { объединения; 5. трудовые коллективы. }\end{array}$ & $\begin{array}{l}\text { Гражданин или группа граждан, имеющее } \\
\text { активное избирательное право. }\end{array}$ \\
\hline 4. Стадии & $\begin{array}{l}\text { 1. организационный порядок формиро- } \\
\text { вания инициативной группы (минималь- } \\
\text { ная численность инициативной группы } \\
\text { граждан не может превышать } 3 \text { процента } \\
\text { от числа жителей муниципального образо- } \\
\text { вания); } \\
\text { 2. рассмотрение органом местного са- } \\
\text { моуправления или должностным лицом } \\
\text { местного самоуправления, к компетенции } \\
\text { которых относится принятие соответству- } \\
\text { ющего акта; } \\
\text { 3. регистрация гражданской инициативы; } \\
\text { 4. сбор подписей в поддержку гражданской } \\
\text { инициативы; } \\
\text { 5. составление итогового протокола и } \\
\text { утверждение бланка подписного листа; } \\
\text { 6. официальное опубликование мотивиро- } \\
\text { ванного решения, принятого по результа- } \\
\text { там рассмотрения правотворческой иници- } \\
\text { ативы, в городской газете. }\end{array}$ & $\begin{array}{l}\text { 1. организационный порядок формирова- } \\
\text { ния инициативной группы; } \\
\text { 2. рассмотрение гражданской законода- } \\
\text { тельной инициативы избирательной ко- } \\
\text { миссией или комиссией представительного } \\
\text { органа местного самоуправления; } \\
\text { 3. регистрация гражданской инициативы; } \\
\text { 4. установление сроков сбора подписей; } \\
\text { 5. утверждение бланка подписного листа. }\end{array}$ \\
\hline
\end{tabular}

содержание и назначение. От идеи концепцию отличает главным образом то, что она непосредственно связана с самим законопроектом, соизмерима с ним в основных его параметрах [6].

Концепцию законопроекта следует определять как аналитическую нормативную модель с вариантами правового поведения, с примерной структурой акта, его связями с другими актами, возможными последствиями и оценкой эффективности действия, т.е. концепцию законопроекта можно определить как документ, представляющий собой теоретическое обоснование необходимости его принятия, которое вырабатывается на основе «идеи законопроекта», практических результатов развития общественных отношений, являющихся предметом правового регулирования закона. По верному замечанию И.Ф. Казьмина, «в концепции идея уже в значительной мере материализована, воплощена в ведущих признаках будущего акта». Таким образом, концепция законопроекта, это своего рода «идейная модель» будущего законодательного акта, задающая цели и основные параметры его содержания [7].

Схематично рассмотренные выше понятия, их соотношение можно изобразить следующим образом: (рисунок 2).

Таким образом, правотворческий процесс представляет собой процессуальный симбиоз законотворчества и законодательства. Законодательная инициатива как начальное звено законодательного процесса выступает в качестве медиума во взаимодействии государства и гражданского общества. Ведь прежде чем выразить закон нормативно, ему необходимо дать социологическое обоснование, вывести его из запросов общественной жизни. Тем самым, необходимо дальнейшее совершенствование законодательного процесса, в том числе института законодательной инициативы, поскольку без этого построение в России гражданского общества и правового государства невозможно. 


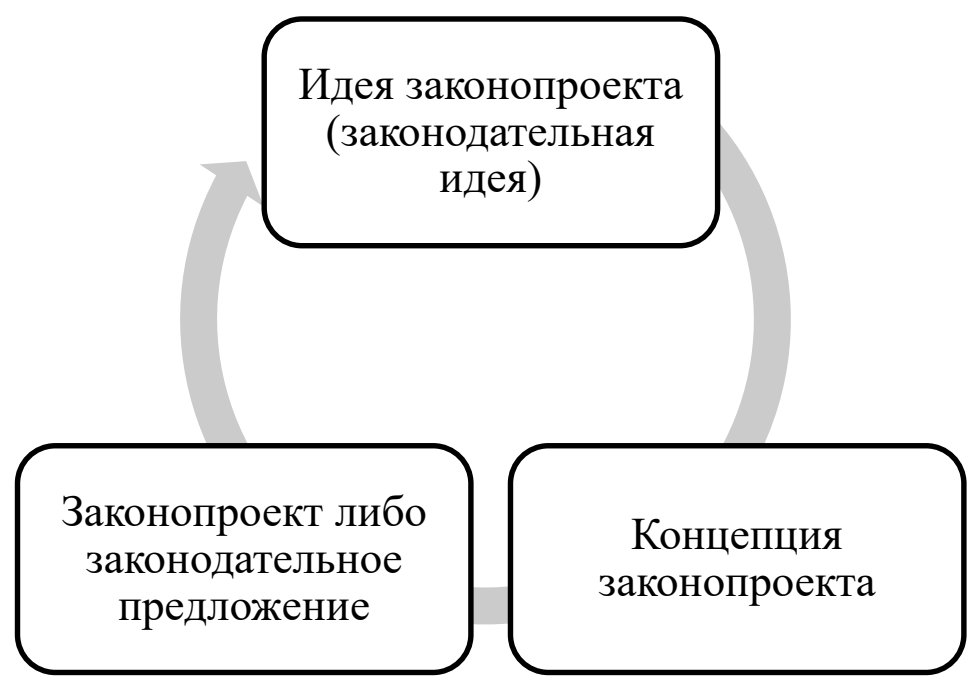

Puc. 2. Стадии законопроектного процесса

Таблица 3. Сравнительно-правовая характеристика понятий «идея законопроекта» и «концепция законопроекта»

\begin{tabular}{|l|l|l|}
\hline $\begin{array}{c}\text { Отличительные } \\
\text { признаки }\end{array}$ & \multicolumn{1}{|c|}{$\begin{array}{c}\text { Законодательная идея } \\
\text { (идея законопроекта) }\end{array}$} & \multicolumn{1}{|c|}{ Концепция законопроекта } \\
\hline 1. Сущность & $\begin{array}{l}\text { Выступает в качестве инструмента проек- } \\
\text { тирования качественного и эффективного } \\
\text { законодательства. }\end{array}$ & $\begin{array}{l}\text { Выполняет системную } \\
\text { организацию нормативного материала, его } \\
\text { оптимальную структурированность. }\end{array}$ \\
\hline $\begin{array}{l}\text { 2. Предметно- } \\
\text { содержательная } \\
\text { характеристика }\end{array}$ & $\begin{array}{l}\text { Научно обоснованная интегративная ха- } \\
\text { рактеристика целей, предмета и способов } \\
\text { правового регулирования проектируемого } \\
\text { закона. }\end{array}$ & $\begin{array}{l}\text { Правовое, организационное, финансово-э- } \\
\text { кономическое обоснование законопроекта. }\end{array}$ \\
\hline 3. Цель & Меры превентивного характера. & Меры прогностического характера. \\
\hline 4. Тип & Социальная квазинормативность. & Правовая нормативность. \\
\hline 5. Форма & Формальная незакрепленность. & Нормативная формула. \\
\hline
\end{tabular}

\section{Библиографический список}

1. Законотворчество в Российской Федерации (научно-практическое и учебное пособие) / под ред. А.С. Пиголкина.-М., 2015.- 226 с.

2. Карпов Н.Н. Законодательный процесс в Российской Федерации. Москва. 2017. 347 с.

3. Колдаева Н.П. Законодательная инициатива как правовой институт: автореф: дис. канд. юрид. наук / НЛТ. Колдаева. Москва. МГУ. 2014. 159 с.

4. Кривенко Д. Т. Право законодательной инициативы // Государство и право. 2012. № 3. С. 3.

5. Лебедев В.А. Реализация права законодательной инициативы субъектов Российской Федерации // Конституционное и муниципальное право.-2016. № 5. С. 65.

6. Лихачев С.А. О понятиях «законотворческий процесс», «законодательная процедура», «законодательный процесс» // Парламентские процедуры: проблемы России и зарубежный опыт / Под ред. проф. С.А. Авакьяна. Москва. 2015. 671 с.

7. Нашиц А. Правотворчество: теория и законодательная техника. Москва. 2016. 